\title{
AN EXPLORATORY STUDY ON THE RELATIONSHIP BETWEEN DIGITAL GAMES AND TRANSFER OF LEARNING
}

\author{
C. Frank Lee, University of Mary Hardin-Baylor, flee@umhb.edu \\ Rebecca Giorcelli, Fairmont State University, Rebecca.Giorcelli@fairmontstate.edu
}

\begin{abstract}
Even though games are believed to hold the potential to render learning more learner-centered, more interesting, and more effective, the relationship between playing digital games in the classroom and transfer of learning is still unclear. By deploying a qualitative study using college students who play games that encompass curricular objectives, this case study finds that there is a positive relationship between playing digital games and transfer of learning.
\end{abstract}

Keywords: Transfer of Learning, Digital Games, Near Transfer, Far Transfer

\section{INTRODUCTION}

The rapid advances of technologies have created a new learner generation who think and learn differently. The emergence of this 'digital native' generation has fundamentally changed the way students think and process information, thus making it difficult for them to excel academically using outdated teaching methods. Consequently, student motivation and engagement have become an ongoing challenge for classroom instructors [6].

A substantial body of literature indicates that the use of non-traditional interventions, such as games, simulations, and multimedia instruction, are valuable teaching methods to hold this new generation's attention [7]. Especially, gaming is considered an effective, fun, and encouraging way of learning while providing immediate feedback and measurable process. Therefore, games in the classroom are not just played for fun but used as learning tools that can engage students' interest and immerse them in subject knowledge.

Even though it has been reported that games encompassing curricular objectives are believed to hold the potential to render learning more learner-centered, more interesting, and more effective [9], the relationship between playing digital games in the classroom and transfer of learning is still unclear. Many earlier studies have focused on learning from games within a specific subject or knowledge gain but transferring knowledge learned or gained from playing games to new circumstances is still questionable.

The purpose of this study is to investigate the relationship between playing digital games and transfer of learning by examining the effectiveness of the use of digital games for student satisfaction and for measurable academic improvement. To accomplish the objective, this study conducts a case study using a group of students who play a specially designed digital game before participating in the real world project.

\section{BACKGROUND}

\section{Game as a Teaching Tool}

Gaming is an effective, fun, active, and encouraging way of learning, providing immediate feedback and measurable process. Therefore, games in the classroom are not just played for fun, but instead used as learning tools that can engage students' interest and immerse them in subject knowledge [7]. As a result, educators have been experimenting with these gaming environments to examine their place in the classroom.

Klassen and Willoughby [5] point out that the use of learning games is consistent with the philosophy of "active learning" which many educational authorities have advocated. According to Prensky [12], the use of educational games is necessary to connect with the "video game generation" who do not respond to traditional instructional 
approaches such as lecture. Web-based learning games would seemingly have substantial appeal to the "digital generation" of younger students who have grown up playing computer and video games. Kirk [4] finds that instructors at both the college and secondary levels are increasing their use of games in an effort to motivate learners and teach complex concepts.

Games that encompass curricular objectives are believed to hold the potential to render learning more learnercentered, easier, more enjoyable, more interesting, and, thus, more effective [9]. Specifically, games constitute potentially powerful learning environments for several reasons [8]: (a) they can support active, experiential, problem-based learning, (b) they provide immediate feedback enabling players to learn from their actions, (c) they encompass opportunities for self-assessment through the mechanisms of scoring and reaching different levels, (d) they increasingly become social environments involving communities of players and (e) they can favor the development of various skills, such as critical thinking and problem-solving skills.

\section{Transfer of Learning}

Transfer of Learning is the application of skills, knowledge, and/or attitudes that were learned in one situation to another learning situation [10]. Transfer of learning is a phenomenon of learning more quickly and developing a deeper understanding of the task if we bring some knowledge or skills from previous learning to a new learning situation. The theory implied that transfer of learning depends on how similar the learning task and transfer tasks are.

Transfer of learning can be divided into two categories, near and far. According to Perkins and Salomon [11], "near transfer refers to transfer between very similar contexts" (p. 3). Near transfer of skills and knowledge are applied the same way every time the skills and knowledge are used. Far transfer, on the other hand, "refers to transfer between contexts that, on appearance seem remote and alien to one another" [11, p. 3]. Far transfer tasks involve skills and knowledge being applied in situations that change. Far transfer tasks require instruction where learners are trained to adapt guidelines to changing situations or environments.

\section{Game and Transfer of Learning}

Washbush \& Gosen [14] found that there was no relationship between learning and simulation performance in far transfer in their five-year longitudinal study with college students examining the effectiveness of a business enterprise simulation game. Another study, Barab, et al. [2] suggests statistically significant gains in near-transfer performance tests but not in far transfer standards based academic achievement tests. Also, Alkan \& Cagiltay [1] conducted a mixed-method study with college students to explore game-based cognitive processes using a puzzle game and concluded that in an informal learning situation, trial-and-error strategies were mostly used with cognitive gains being seen in the near transfer.

\section{RESEARCH METHODOLOGY}

To accomplish the research objective, this study deploys a qualitative study using a group of students who volunteered to play the IBM CityOne game as a tool to prepare for a budget management skills-based project. A case study is conducted for exploring the factors and a semi-structured interview is conducted for data gathering in this case study.

CityOne was developed by IBM as a tool for teaching $21^{\text {st }}$ century specific skills (Figure 1). The game places the audience in the seat of CEO, addressing issues of the energy, water, banking and retail industries. Working toward developing a smarter future, the player is exposed to the benefits of long-term planning, creative thinking, competitive customer service, and sustainable practices. By allowing the audience to see the consequences of their decisions in real-time, CityOne is a great supplement to traditional education methods. 


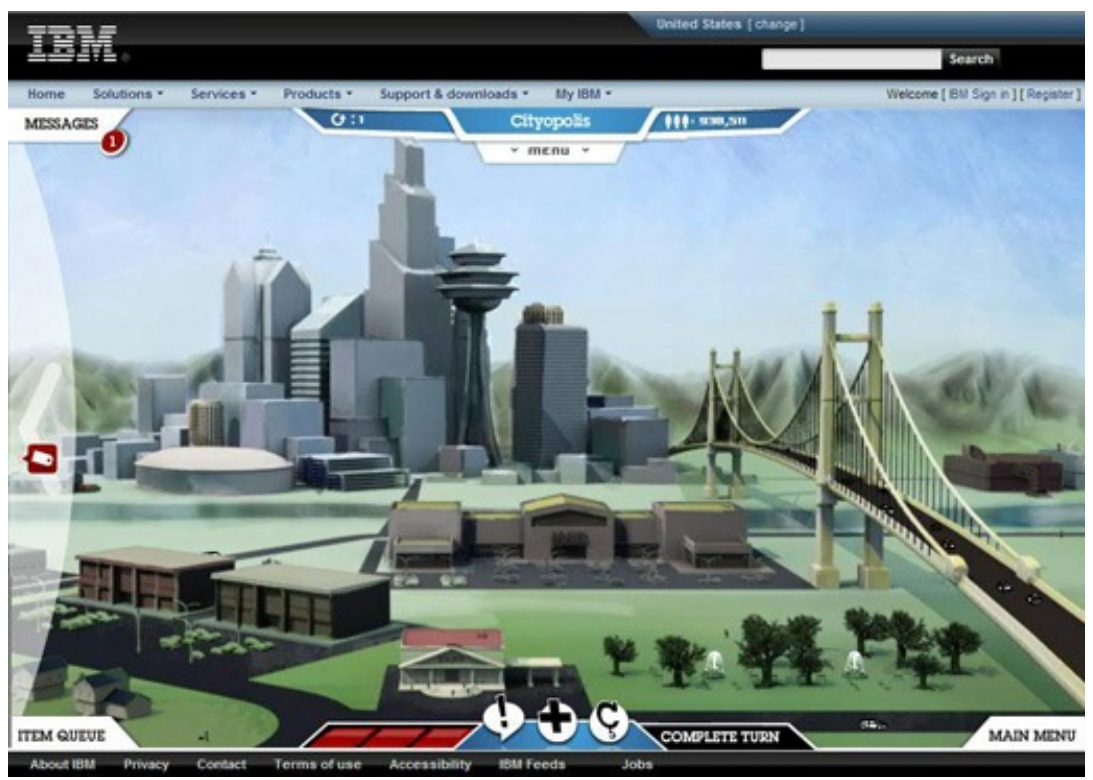

Figure 1: CityOne Dashboard (Source: ibm.com/cityone)

CityOne is adopted for a senior classroom at an Eastern University in the US as a training tool to prepare a real world project in which budgeting and resource allocation are essential skills. Since the main objective of CityOne is resource allocation, developing budget management skills is crucial for game players. In the game, gamers must thoughtfully manage the budget being careful not to overspend, because if the gamer overspends he or she will not have enough credits to implement costly actions in the latter half of the game. In order for gamers to improve their resource allocations skills, they must constantly examine the city's budget for the various industries in order to get accustomed to being conscience of available resources.

Twelve students volunteered to play the CityOne game before participating in a budget management project. Table 1 shows the demographic descriptions of respondents. Students were interviewed on their experiences before and after playing the game as well as after the completion of the project. These interviews were 15 to 20 minutes long and consisted of a standard set of questions, including:

- How did you feel about playing games as a part of class activities in your class before playing this game?

- How do you feel about using games as a part of class activities in your class after playing this game?

- How did the game impact your learning?

- Compare the interest, motivation, etc. to that of a traditional lecture?

- Do you think this game is a worthwhile learning experience?

- What is the most important thing you learned from the game?

- Did the Cityone game help you in the budgeting function of your project? How?

- Did the Cityone game help you any other areas of your campaign?

Table 1. Demographic Descriptions of Respondents

\begin{tabular}{|c|c|c|}
\hline Demographic characteristics & & Responses \\
\hline \multirow[t]{2}{*}{ Gender } & Male & 6 \\
\hline & Female & 6 \\
\hline \multirow[t]{3}{*}{ Age } & $18-22$ years & 8 \\
\hline & $23-27$ years & 3 \\
\hline & $28-32$ years & 1 \\
\hline
\end{tabular}




\section{RESULTS}

Data were collected and coded using NVivo9. NVivo9 was chosen by the study researchers because of its capability to enable the researchers to import quantitative data (responses to a structured instrument) into the program and integrate it with the qualitative data. NVivo9 assisted in providing a greater understanding of the study findings, enabled us to explore the convergence and divergence of our data, and helped to identify areas that need to be explored further if we are to fully understand the concepts of transfer of learning.

\section{How did you feel about playing games as a part of class activities in your class before playing this game?}

The results show that twice as many student responses were positive when compared to both the neutral and negative responses combined. Eight of the twelve students $(66.6 \%)$ responded positively to the question. Seven of the eight $(87.5 \%)$ used statements in their responses that related game-based learning to "fun", "exciting", or "enjoying" or stated "games are a great way to learn". The eighth student indicated not having an opportunity to play games often and felt it would be a great activity. Two students (16.7\%) were neutral with respect to playing games as part of class activities. These students reported they didn't really think about it much beforehand. One student wondered whether or not it would be beneficial. Two students (16.7\%) were negative about playing games as part of class activities before playing the game. One student was not convinced about the effectiveness on learning and one student felt it would be a change from lecture and enjoyed playing games but not as part of everyday class activities.

\section{How do you feel about using games as a part of class activities in your class after playing this game?}

We found that all student responses were positive toward using games as part of class activities with the exception of one student who wasn't sure if learning from the game was as effective as learning from a lecture. Eleven of the twelve students $(92.0 \%)$ responded positively to the question with five of the eight $(62.5 \%)$ using statements in their responses that related game-based learning to "fun", "exciting", or "enjoying" or stated "games are a great way to learn". After playing the game, positive responses were more related to being a "creative learning activity", providing an "improved change over lecture", "maintaining attention", and providing "opportunities for hands-on learning". One student $(0.08 \%)$ was neutral with respect to playing games as part of class activities. The response stated, "It adds a new dimension to the class. I do not think I learned as much as a lecture, but it provided decent feedback to how I think."

\section{How did the game impact your learning?}

The response results for this question were broken down into three categories (Figure 2): business logic \& decisionmaking, budgeting, and game strategy \& conclusion. The majority of students indicated that the impact on learning was related to business logic and decision-making.

Business Logic \& Decision-Making: Seven of the students (58.3\%) gave responses that the impact on learning from playing the game was related to decision-making or business logic. Of these seven students, four of them specifically indicated that the game helped them to understand how the consequence of one decision can influence many future decisions.

Budgeting: Three of the twelve students (25.0\%) gave responses that the impact on learning from playing the game was related to the topic of budgeting. These students indicated that they learned to spend money wisely and that the most expensive solution is not always the best.

Game Strategy \& Conclusion: Two students (16.7\%) gave responses that the impact on learning from playing the game was directly related to game-based strategies and conclusions. One indicated that there was never enough time or money to do everything you want and the other believed insight was gained on what to do next time. 


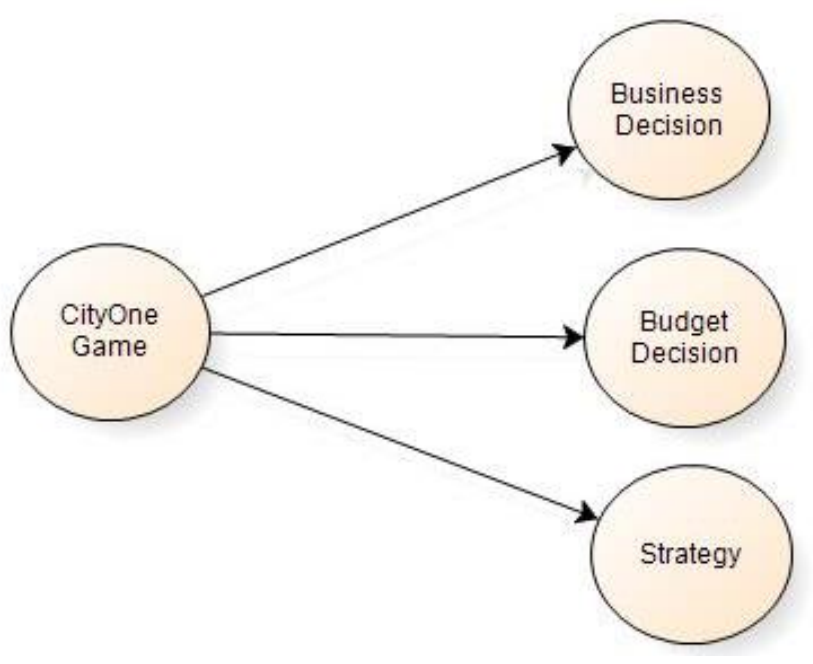

Figure 2. The Impact of Playing CityOne Game

\section{Compare the interest, motivation, etc. to that of a traditional lecture?}

All of the student responses indicated the hands-on learning approach related to the game is preferred over the passive learning style as related to the traditional lecture approach (Figure 3). Figure 3 displays the threedimensional cluster map where similar items are clustered together and different items are further apart. In the 3D cluster map, more frequently occurring word are displayed in larger circle. The cluster map is generated using an iterative multidimensional scaling algorithm. Initially, the items are placed randomly as data points in a square or cube, and then a series of iterations are performed to optimize the positions of the items. At each iteration, the actual distance between each pair of items is compared to the optimal distance between them, and the data points are moved closer together or further apart accordingly. The algorithm ends when an optimal configuration is reached that cannot be improved by further movement of the data points. Responses indicated that traditional lectures are "boring" and "difficult to pay attention to" whereas the game was "interesting" and "fun" and the students were "more involved". One student response stated that it was "more of a game than a learning experience" and wasn't sure how learning would be tested.

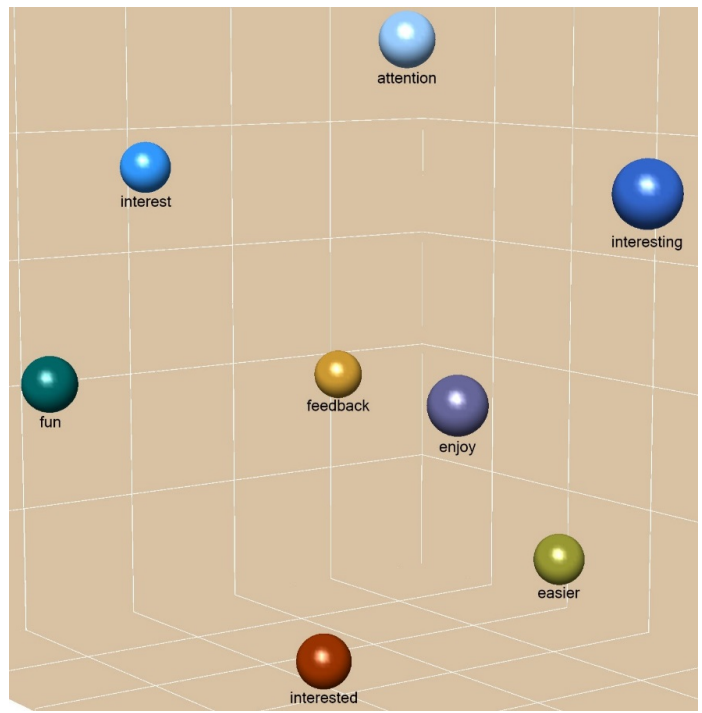

Figure 3. Cluster Analysis on Games vs. Traditional Lecture 


\section{Do you think this game is a worthwhile learning experience?}

Six students simply replied yes it was a worthwhile experience. Four students provided reasoning such as "because you learn faster when you actually get to apply the lessons you learn in the class to a real world problem or issue", "because it showed the reactions in a variety of areas after making a particular decision", "because it gives you the opportunity to make big decisions", and "[because] some of the concepts were better illustrated by the animation of the game... venturing outside of the box for learning lessons helps spark interest as well...". One student (9.0\%) responded that "yes" it was a worthwhile experience "if there is more feedback about how I did and what my choices in the game meant".

\section{What is the most important thing you learned from the game?}

The response results for this question were broken down into four categories: business logic \& decision-making, budgeting, game strategy \& conclusion, and general/vague. The majority of students indicated that the impact on learning was related to business logic \& decision-making. Several students gave responses that overlapped categories. Eight of the students $(66.7 \%)$ gave responses that the most important thing learned from the game was related to decision-making or business logic. These students gave responses related to making better decisions, making the right decision, assessing options to resolve problems, making the best overall choice, and considering the consequences of decisions. Four of the twelve students (33.3\%) gave responses that the most important thing learned from the game was related to budgeting. These students gave responses related to making financial decisions, managing money, spending a budget, and learning about money and credits. Two students (16.7\%) responded with statements that were quite general and vague such as "what not to do" and "what would you think is needed to improve in life and others". One student (8.3\%) response was directly related to the game strategy and learned "what needs to be done if my city is about to die!!!”

\section{Did the Cityone game help you in the budgeting function of your project?}

We found that most responses specified that the game did help in the budgeting function because it allowed students to see the effects of budgeting decisions (Figure 4). One student indicated that the game helped to see the importance of "prioritizing" for a budget. Another student specified that the "discussions and tips" within the game helped to analyze budgeting decisions. Other comments were related the benefit of the game in helping students realize that spending too much money too quickly prevents students from advancing in later stages of the challenge. "We had to spend it in the areas that are the most important to achieve the best possible outcome."

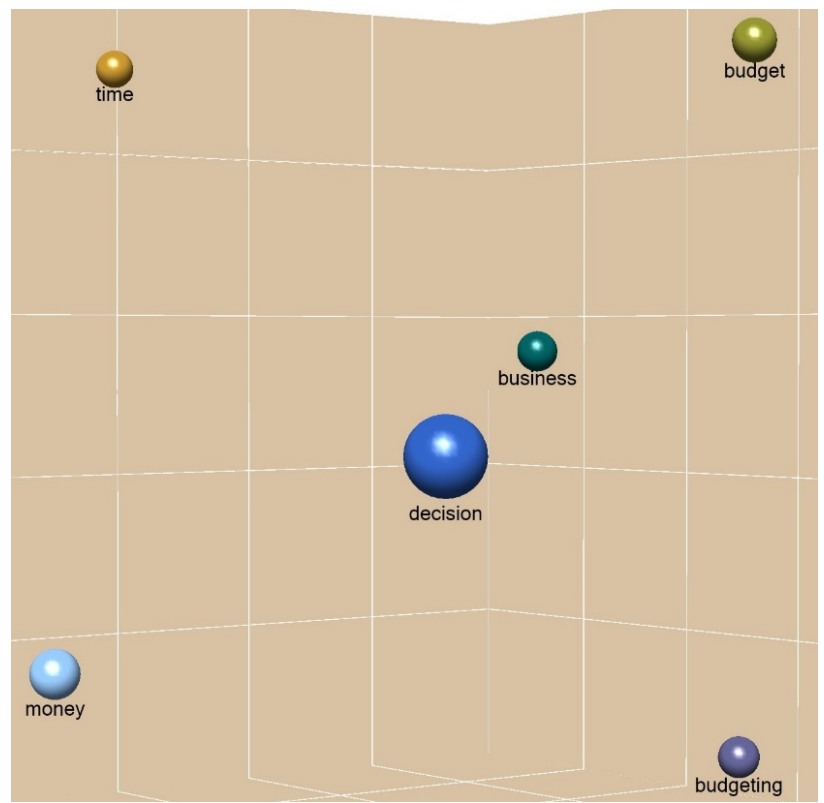

Figure 4. Cluster Analysis on Near Transfer of Learning 


\section{Did the Cityone game help you any other areas of your campaign?}

Eleven students (84.6\%) responded positively to the question. Nine of the students specifically responded that the game helped with decision-making or problem-solving (Figure 5). Figure 5 displays the word trees which show the results as a tree with branches representing the various contexts in which the word or phrase occurs. The larger the size of the font indicates its frequency, the larger the more frequent. Two of the students specified that the game helped with time management. One student response (7.7\%) was considered neutral to this question stating, "I didn't notice that, but in my life it did make some help."

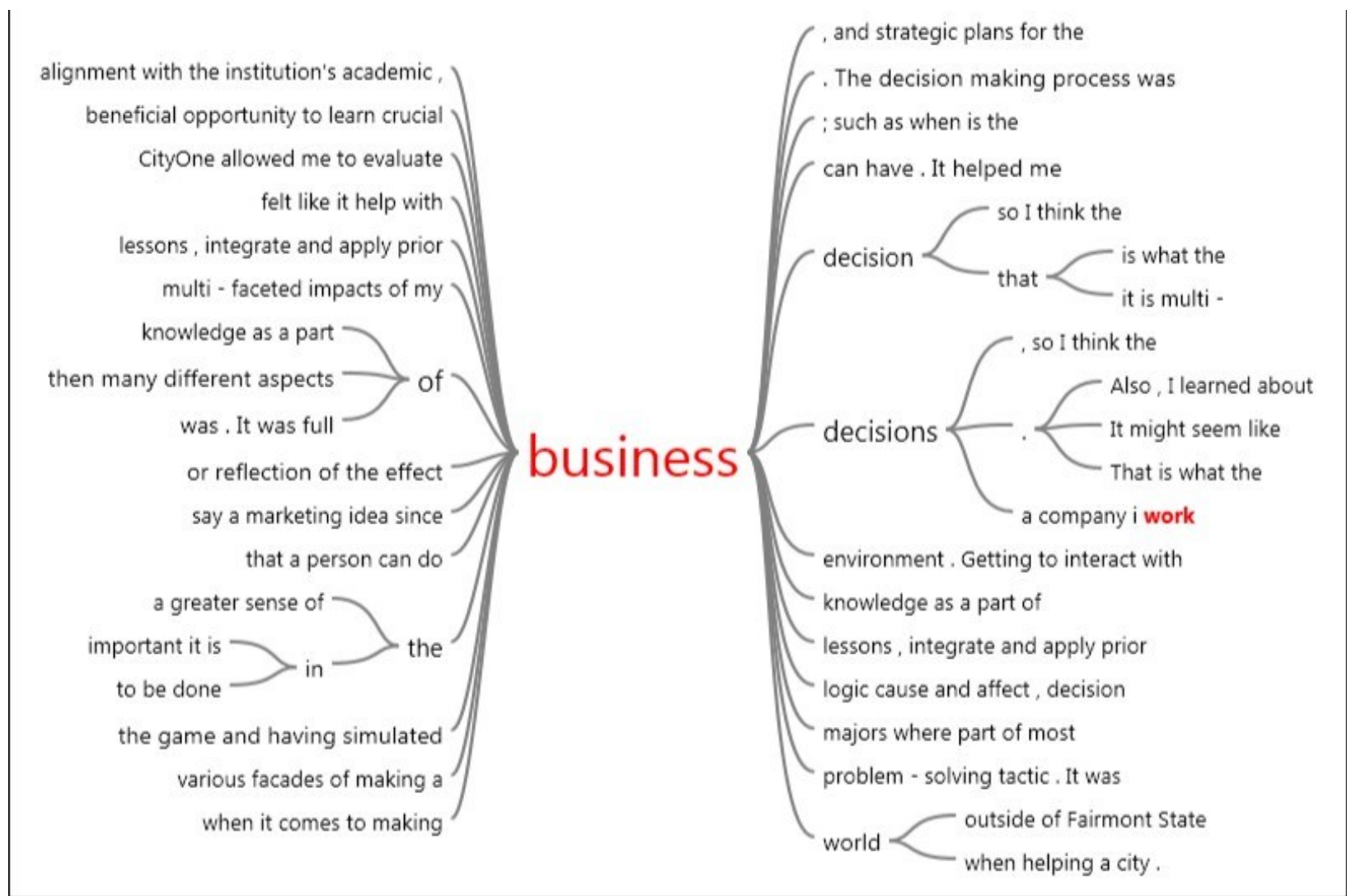

Figure 5. Text Search Query Result on Far Transfer of Learning

\section{CONCLUSIONS}

Motivated by a need to understand the role of playing digital games in the classroom, this case study finds that there is a positive relationship between playing digital games and transfer of learning even though the relationship is mainly with near transfer. The results indicate that the CityOne game activity was a positive, worthwhile learning experience for students and did help to prepare them for the budget management project. Student attitudes toward using games for learning tended to improve based upon this experience. The most significant learning from the CityOne game was related to a better understanding of business logic, decision-making and budgeting. Based upon student feedback, playing the CityOne game multiple times is an effective teaching strategy to prepare students for the budget management project.

This research has unique contributions for researchers and practitioners. First, this case study is one of few qualitative studies conducted to find the relationship between playing digital games and transfer of learning. Prior studies heavily used quantitative approaches to measure the effectiveness of simulation games. This study also contributes to understanding the nature of student attitudes toward using games for learning. Unlike many prior 
studies which present only a snapshot of the role of playing digital games, this study presents and discusses how student attitudes toward using games for learning are changed over time.

\section{REFERENCES}

1. Alkan, S., \& Cagiltay, K. (2007). Studying computer game learning experience through eye tracking. British Journal of Educational Technology, 38(3), 538-542.

2. Barab, S., Sadler, T., Heiselt, C., Hickey, D., \& Zuiker, S. (2007). Relating narrative, inquiry, and inscriptions: Supporting consequential play. Journal of Science Education \& Technology, 16(1), 59-82.

3. Gararneau, L. 2014 Global Gaming Stats: Who's Playing What, and Why? January 16, 2014. Retrieved March 11, 2015, from http://www.bigfishgames.com/blog/2014-global-gaming-stats-whos-playing-what-and-why

4. Kirk, JJ. "An Unofficial Guide to Web-based Instructional Gaming and Simulation Resources," ERIC Document Reproduction Service ED472675, 2001.

5. Klassen, KJ. and K.A. Willoughby. (2003) "In-class Simulation Games: Assessing Student Performance," Journal of Information Technology Education, 2, pp. 1-13.

6. KUMAR, R. \& LIGHTNER, R. (2007) 'Games as an Interactive Classroom Technique: Perceptions of Corporate Trainers, College Instructors and Students', International

7. Journal of Teaching and Learning in Higher Education, 19(1): 53-63

8. Nemerow, L. G. (1996). Do classroom games improve motivation and learning? Teaching and Change, 3(4), 356-366.

9. Oblinger, D. (2004) The next generation of educational engagement. Journal of Interactive Media in Education, 8: 1-18.

10. Papastergiou, M. (2009) Digital Game-Based Learning in high school Computer Science education: Impact on educational effectiveness and student motivation. Computers \& Education, 52: 1-12.

11. Perkins, D.N. (1992). Smart schools: From training memories to educating minds: New York: The Free Press.

12. Perkins, D. N., \& Salomon, G. (1992). The science and art of transfer. If minds matter: A foreword to the future, 1, 201-210.

13. Prensky, M. Digital Game Based Learning. New York: McGraw-Hill, 2000. ISBM: 0071363440.

14. Perkins, D. N., Salomon, G. (1992). Transfer of Learning. Contribution to the International Encyclopedia of Education, Second Edition. Oxford, England: Pergamon Press.

15. Washbush, J., \& Gosen, J. (2001). An exploration of gamederived learning in total enterprise simulations. imulation \& Gaming, 32(3), 281. 